\title{
Experiencia digital de los adultos mayores frente al covid-19: El caso del programa universidad para los mayores de la Universidad Autónoma de Nuevo León, México
}

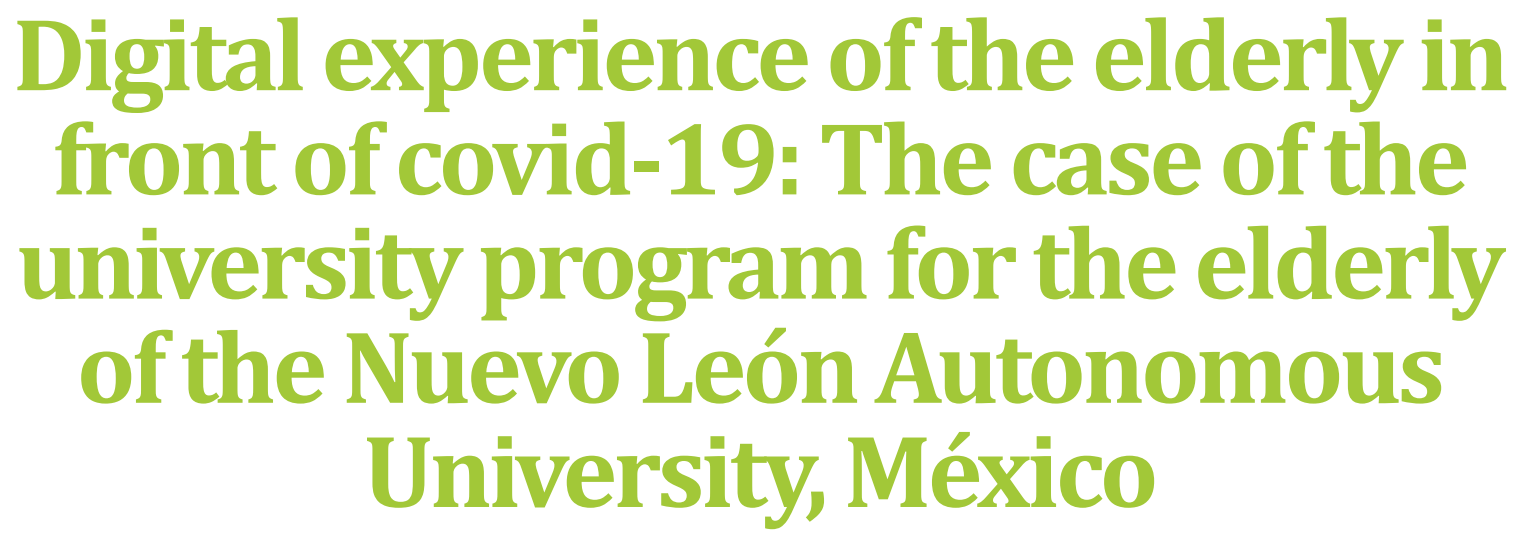

Luz Amparo Silva Morín ${ }^{1}$

Luz Alejandra Escalera Silva ${ }^{2}$

Raúl Eduardo López Estrada ${ }^{3}$

Universidad Autónoma de Nuevo León

\section{RESUMEN}

Se analiza la experiencia digital en la educación para adultos mayores frente al Covid-19. Para ello se examinan aquellos elementos que podrían favorecer la continuidad de estos programas a distancia. Se tomó como estudio de caso el Programa Universidad para los Mayores UANL. En la conclusión se destaca que la experiencia digital durante la pandemia fue exitosa, no

$1 \quad$ Maestría en Trabajo Social por la Universidad Autónoma de Nuevo León, Profesora de la Facultad de Trabajo Social y Desarrollo Humano, Universidad Autónoma de Nuevo León, México. Contacto: luz.silvamr@uanl.edu.mx ORCID: https://orcid.org/0000-0003-0987-7557

2 Doctora en Métodos Alternos de Solución de Conflictos por la Universidad Autónoma de Nuevo León, Profesora de la Facultad de Trabajo Social y Desarrollo Humano, Universidad Autónoma de Nuevo León. México.

Contacto: luz.escaleraslv@uanl.edu.mx https://orcid.org/0000-0002-3214-2834

3 Doctor en Antropología por la Universidad Laval, Profesor de la Facultad de Trabajo Social y Desarrollo Humano, Universidad 3Autónoma de Nuevo León, México. Contacto: raul.lopezest@uanl.edu.mx https://orcid.org/0000-0002-5534-8827 
obstante en la consideración de una continuidad del programa se deberán tomar en cuenta factores de riesgo asociados a los factores del entorno, los factores técnicos: educación e informática y el interés en educación presencial.

\section{ABSTRACT}

The digital experience in education for older adults compared to Covid-19 will be analyzed, for which those elements that could favor the continuity of these distance programs are examined. The UANL University for the Elderly Program was taken as a case study. The conclusion highlights that the digital experience during the pandemic was successful, however in considering a continuity of the program, risk factors associated with environmental factors, technical factors: education and information technology, and interest should be taken into account. in classroom education.

PALABRAS CLAVE: Educación, Educación a distancia, adultos mayores, Nuevo León, COVID-19.

KEY WORDS: Education, Distance education, older adults, Nuevo León, COVID-19.

\section{INTRODUCCIÓN}

Este proyecto de investigación busca analizar la experiencia digital de adultos mayores frente al Covid-19. Para ello se tomará como estudio de caso el Programa Universidad para los Mayores UANL. Con esta intención en las páginas siguientes se buscará problematizar esta temática, que además de ser sugestiva, es actual y cuyos resultados permitirán identificar y esclarecer un el avenir de la educación para adultos mayores.

Es seguro que hoy en día sea más claro el cliché de que nada es igual a la situación anterior: El Covid-19 llegó para cambiar todos los escenarios.
Al mismo tiempo los cambios suscitados nos muestran que las sociedades han comenzado a exigir la no paralización por el virus y un aprendizaje para enfrentar la pandemia y un futuro todavía incierto. En este contexto de transformación acelerada en todos los ámbitos, un sector que fue obligado a responder a la crisis fue el de la educación. Existe consenso entre sus actores de que la formación educativa debe continuar y los sistemas educativos no pueden detenerse o postergarse.

Debido a esto se han desplegado grandes esfuerzos y estrategias para implementar vías de educación virtual en poco tiempo y así se tuvo que migrar a una educación no presencial en los últimos meses abordando nuevas maneras de enseñar y aprender a distancia.

En esta situación el Covid-19 obligó con urgencia a repensar nuestro modo de vida. De aquí surgieron cuestionamientos acerca de cómo seguir con los sistemas educativos durante la pandemia (Ferrante, 2020)

Esto suscitó grandes desafíos. Ante el cierre de centros educativos para evitar la propagación del virus se formularon cuestionamientos acerca de la preparación de actores e instituciones para su inserción en la educación a distancia (Kemelmajer, 2020).

La crisis actual nos ha mostrado las grandes dificultades en lo social y las grandes brechas digitales en relación al acceso y la ausencia o frágil alfabetización digital de gran parte de los docentes y estudiantes. A esto debe sumarse el hecho de que lo virtual es diferente y debe pensarse como otra lógica (Ferrante, 2020).

Bien que la expansión del Covid-19 obligó a la adopción de tecnologías de la comunicación y que la digitalización de la educación dejó de ser una opción y se convirtió en una necesidad para las instituciones es imprescindible mencionar 
que el uso de la tecnología en la educación a distancia no implica la migración al modelo virtual (Atarama, 2020).

A lo anterior deberá agregarse que los docentes y administraciones han tenido que adaptar sus planes de estudio a la educación a distancia, para continuar con el proceso de enseñanzaaprendizaje (Semana, 2020).

Así, la actual situación presenta un panorama en donde convergen nuevas propuestas para los actores de la educación (Silva, 2020)

Uno de los retos a los que se tuvo que hacer frente ante lo imprevisto, fue el reaccionar rápido e implementar sistemas digitales para suplir lo que se realizaba en el modo presencial para continuar con la labor educativa (Silva, 2020).

También, hubo otros desafíos relacionados con el cambio urgente, entre ellos, la posibilidad de acceder a un entorno virtual para la educación en línea, es decir, la posibilidad de que los estudiantes pudieran conectarse desde otros ámbitos (Kemelmajer, 2020). Según el World Economic Forum, sólo alrededor del 60 \% de la población mundial tiene acceso a la red (López, 2020). Asimismo, el confinamiento obligó a la adopción de una modalidad virtual para estudiantes y docentes que reveló una brecha digital (López, 2020).

Lo anterior mostró que la mayoría de las escuelas no estaban preparadas para enfrentar el acceso desigual a Internet. Situación que es tan sólo uno de los muchos problemas de nuestro sistema educativo a nivel global (López, 2020).

De hecho la mayoría de los centros educativos no han puesto en marcha sistemas virtuales en un sentido amplio. Lo que ha sucedido es la implementación de clases con mediación de tecnologías a distancia. Esto indudablemente difiere de una didáctica de lo virtual que implica otros estilos de enseñanza aprendizaje (López, 2020).

En pocas palabras la crisis de la pandemia está exigiendo urgentemente a la escuela responder a "un desafío con el que desde hace años la educación viene lidiando: qué hacer con ese huracán llamado digitalización" (López, 2020).

Las aseveraciones anteriores bien que son válidas para la educación durante la pandemia actual, adquieren un matiz de ciertamente similar a lo que sucede en el ámbito de la educación para los adultos mayores. En este caso, las instituciones educativas dedicadas a la educación de los adultos mayores, ante la situación de crisis, tuvieron que poner en marcha estrategias de educación a distancia con la finalidad de que no se perdiera el semestre lectivo en el que estaban inscritos (Fuerte, 2020).

Esta estrategia indudablemente representó un reto mayúsculo, sobre todo para esta generación que creció fuera de entornos virtuales caracterizados por el internet $y$ tecnologías virtuales (Fuerte, 2020). Esta situación evidentemente es diferente a la de la generación actual quien efectúa muchas de sus acciones cotidianas utilizando las nuevas tecnologías de la comunicación e información (Fuerte, 2020). De aquí entonces la interrogante de cómo se han adaptado los adultos mayores ante el reto de la actual pandemia, sobre todo en lo relativo a los programas de educación que en muchos casos se sigue en Universidades para los Mayores (Fuerte, 2020).

$\mathrm{Y}$ que en algunos casos han tenido que cerrar sus puertas desde hace unos meses, aunque en otros casos han mantenido actividades durante la cuarentena a través del correo electrónico y servicios digitales a través de los cuales se han sostenido servicios de docencia. Uno de los casos de los cuales se dispone de información es el de la Universitat per a Majors (Universidad 
para Mayores) de la Universitat Jaume I (UJI), en Castellón de la Plana, España (Fuerte, 2020).

En este programa se continúan realizando los mismos esfuerzos educativos anteriores a la pandemia, aunque ahora utilizando medios remotos de emergencia para sus estudiantes mayores de 55 años. Para ello, la UJI implementó el Campus Virtual Sénior, habilitando un espacio y continuar virtualmente el ciclo escolar. Con esta acción se garantizó el acompañamiento al adulto mayor durante la crisis sanitaria con la participación del equipo docente y los representantes de los estudiantes quienes iniciaron reuniones virtuales para atender las necesidades educativas relacionadas con la docencia online a través del Aula Virtual de la UJI. Es importante agregar que el aprendizaje en el Aula Virtual depende del propio estudiante, quien asume un rol activo reproduciendo las características del aula presencial.

Paralelamente, otro de los casos significativos de continuidad de su programa educativo es el de la universidad de los mayores ofrecido por la UANL. Este programa ${ }^{4}$ ; está basado en la perspectiva del envejecimiento exitoso, desarrollada por Engler y Peláez (2002), representa un espacio académico al que tienen acceso personas de 55 años o más con categoría de estudiantes regulares de la UANL ${ }^{5}$
Hasta la fecha se puede considerar al programa para adultos mayores de la UANL como una experiencia consolidada, en la promoción de la educación de población adulta en el ámbito internacional ${ }^{6}$ .Se trata de una estrategia en vías de fortalecerse ${ }^{7}$ . (Silva y López, 2014)

Estos casos fueron significativos, dado que durante la pandemia se cerraron universidades y centros educativos en todo el mundo. En esta situación estos programas han tenido que también suspender sus actividades presenciales, y con ello, uno de los pilares de los programas educativos para adultos mayores (Fuerte, 2020)

En el caso de la UANL hubo la intención explicita de continuar sus actividades académicas en forma virtual durante la pandemia Covid-19. Para ello se puso en marcha un equipo técnico quien creó sesiones de capacitación al equipo docente y administrativo, para el uso de la plataforma de Zoom. Estas sesiones fueron realizadas de forma virtual para los profesores y para los estudiantes que quisieran conectarse durante el confinamiento. Asimismo, con esta plataforma, los responsables administrativos monitorearon la carga académica y la efectividad de este sistema.

Estos casos son importantes ya que la continuidad a estos programas, aún frente a una

$4 \quad$ Se trata de un programa que contiene un diplomado de cuatro semestres y cursos en diferentes áreas del conocimiento. Desde su creación en 2011 este programa ha recibido a nueve generaciones en su diplomado, a cada una de las cuales han asistido 30 alumnos, en tanto que 235 personas han asistido a cursos de educación continua.

$5 \quad$ Muchas sociedades están prestando atención al rápido incremento de la población en edad avanzada, sobre todo en los países en vías de desarrollo, donde se está envejeciendo a un ritmo más rápido que en las naciones industrializados (National Institute on Aging, 2001; Didimo y Vela, 2005). En México la transición demográfica ha implicado el envejecimiento poblacional, donde las personas de 60 años o más constituyen el14\% de la población total, situación debida al descenso de la fecundidad y la mortalidad y al aumento de la esperanza de vida. Para el año 2050 esta población alcanzará el 28\% (Ham, 2003). Estas cifras indican los esfuerzos que deben realizarse en la educación media superior y superior para ofrecer oportunidades a esta población que anteriormente era atendida solo parcialmente.

$6 \quad$ Véanse los trabajos reportados en la Universidad de Salamanca (1999): Encuentros Nacionales de Programas Universitarios para Personas Mayores; Universidad de Alicante: Actas del IV Congreso Iberoamericano de Universidades para Mayores (2011); Universidad de Zamora (2004): Encuentros Nacionales de Programas Universitarios para Personas Mayores; y Universidad de Valladolid (2011): Jornadas sobre Asociacionismo en los Programas Universitarios de Mayores.

$7 \quad$ Hasta el 2013 el programa Universidad para los Mayores registró un incremento en la demanda. En la primera generación hubo 39 interesados; en la segunda, 55; en la tercera y actual generación, 75. Esto demuestra el interés creciente por el programa, aunque sólo se aceptan 30 estudiantes por generación. En cada una de ellas la proporción de hombres y mujeres se ha mantenido con pequeñas variaciones: $30 \%$ hombres y $70 \%$ mujeres. Las edades en los tres grupos van de los 55 a los 69 años. Puede agregarse a estas cifras que la deserción escolar fue mínima; la mayor incidencia se debió a motivos de salud y de trabajo. Desde el punto de vista de los estudiantes se ha constatado, por medio de encuestas internas, una satisfacción explícita en los cursos del diplomado, situación que confirma resultados de investigación obtenidos por Arnay, Marrero y Fernández (2011). 
crisis sanitaria a nivel mundial, es fundamental para apoyar a la población adulta mayor que está creciendo a pasos acelerados. De aquí que los programas para adultos mayores sean más importantes que nunca en los próximos años.

\section{PREGUNTA DE INVESTIGACIÓN}

Tomando en cuenta lo anterior, esta investigación buscó responder a dos interrogantes centrales: ¿Cuál fue la experiencia digital de adultos mayores frente al Covid-19?. Es importante destacar que en relación a este programa, vale la pena interrogarse acerca de los cambios ocurridos durante la actual crisis de salud. Al mismo tiempo, concomitantemente es importante interrogarse, a partir de la experiencia vivida, acerca del posible escenario en la continuidad de este programa. Los resultados serán de enorme utilidad para prever posibles escenarios futuros de la educación para los adultos mayores que siguen cursos en las universidades y en otras instituciones educativas.

\section{ESTRATEGIA METODOLÓGICA}

Para el abordaje de estas interrogantes del trabajo se expondrá la experiencia de la Universidad Autónoma de Nuevo León en la educación de adultos mayores así como los posibles escenarios futuros para esta población. Al mismo tiempo que el conocimiento de esta experiencia permitirá, desde el punto de vista prospectivo, prever la posible orientación de estos programas y con ello adelantar acciones que deberán realizarse en el futuro.

Esta investigación seguirá un enfoque hipotético deductivo. Para la primera pregunta se abordará una perspectiva transversal, ex postfacto, con una muestra que abarca la totalidad de la generación actual de estudiantes de la Universidad de los Mayores que han vivido la pandemia, así como una muestra de docentes del programa.
Para ello se aplicarán dos encuestas incluidas en la Evaluación de Programa Virtual con 25 reactivos cada una de ellas (se incluyen en el anexo). La primera fue dirigida a estudiantes actuales de Programa; en tanto que la segunda se administró A profesores. Estas encuestas se realizaron durante la primera semana del mes de junio 2020.

El equipo de investigación estuvo constituido por la Directora del Programa Luz Amparo Silva Morín, quien fungió como responsable y con la participación de la Dra. Luz Alejandra Escalera Silva y del Dr. Raúl Eduardo López Estrada, docentes-investigadores de la Facultad de Trabajo Social y Desarrollo Humano de la UANL, quienes fungieron como asesores de investigación. La información resultante del proyecto de investigación fue procesada con el paquete de información estadística: SPSS para el tratamiento de datos cuantitativos.

Se previeron dos entregables de esta investigación: un artículo publicable en una revista arbitrada e indexada, en donde se consignen los resultados de la investigación. Asimismo, se consideró la realización de una mesa redonda para la discusión de los resultados con la participación de expertos, en las instalaciones de la Universidad para los Mayores de la UANL.

\section{RESULTADOS: LA EXPERIENCIA DIGITAL DE LOS ADULTOS MAYORES DEL PROGRAMA UNIVERSIDAD PARA LOS MAYORES DE LA UANL ANTE EL COVID-19.}

La población entrevistada está formada por 61 alumnos del Programa Universidad para los Mayores con edades entre 55 y más de 80 años. La información obtenida muestra que el grupo más grande representó $41 \%$ del total, con edades entre 60 y 64 años; después, el grupo entre 65 y 69 años de edad $21 \%$ de los casos; en seguida, el grupo entre 55 y 59 años agrupó al $15 \%$ de los casos. Sumados totalizaron $77 \%$. 


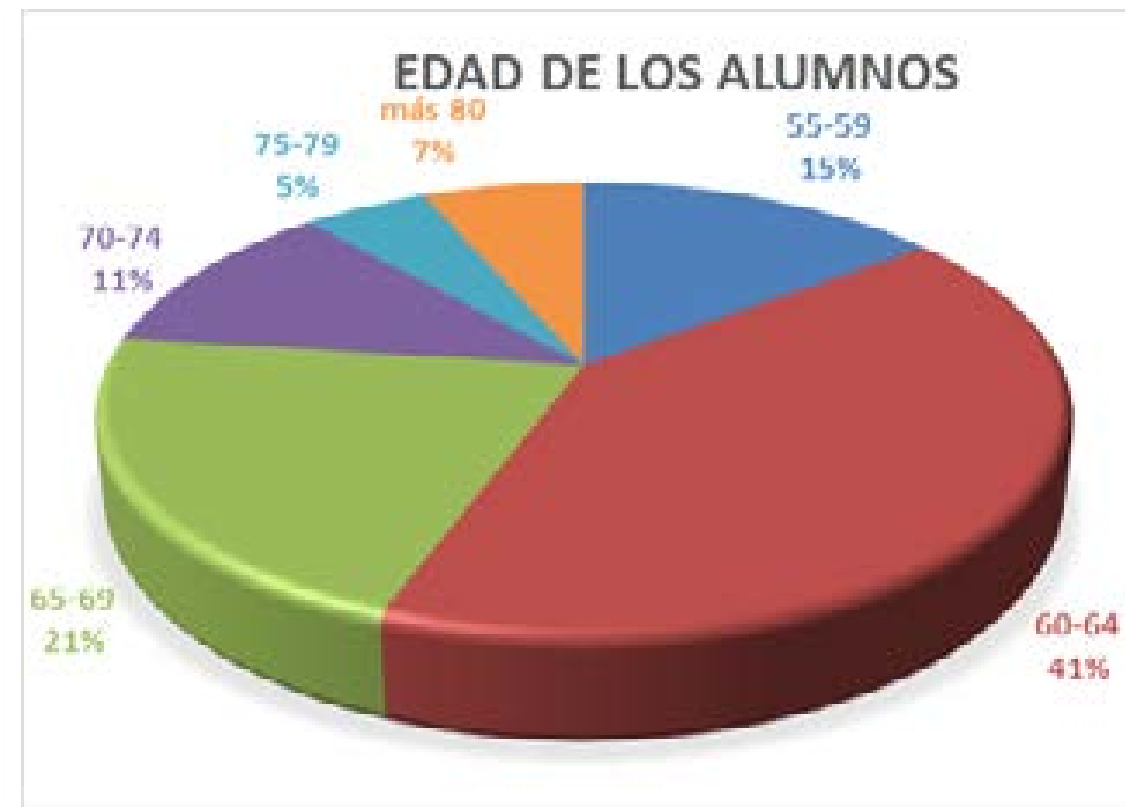

Ilustración 1. (Elaboración propia)

En el grupo entrevistado es notable el alto número de años de escolaridad si lo comparamos con el promedio nacional que es de 7 años. En la siguiente gráfica, se puede observar que el nivel medio superior constituido por Preparatoria y Educación Técnica, significó el 44 \% (12 años de escolaridad) ocupando el lugar más importante; seguido por la Licenciatura y Maestría $35 \%$ (17 y 19 años al menos de escolaridad). Posiciones más modestas fueron ocupadas por: Secundaria $10 \%$, otro $8 \%$ y en último lugar Primaria con $3 \%$.

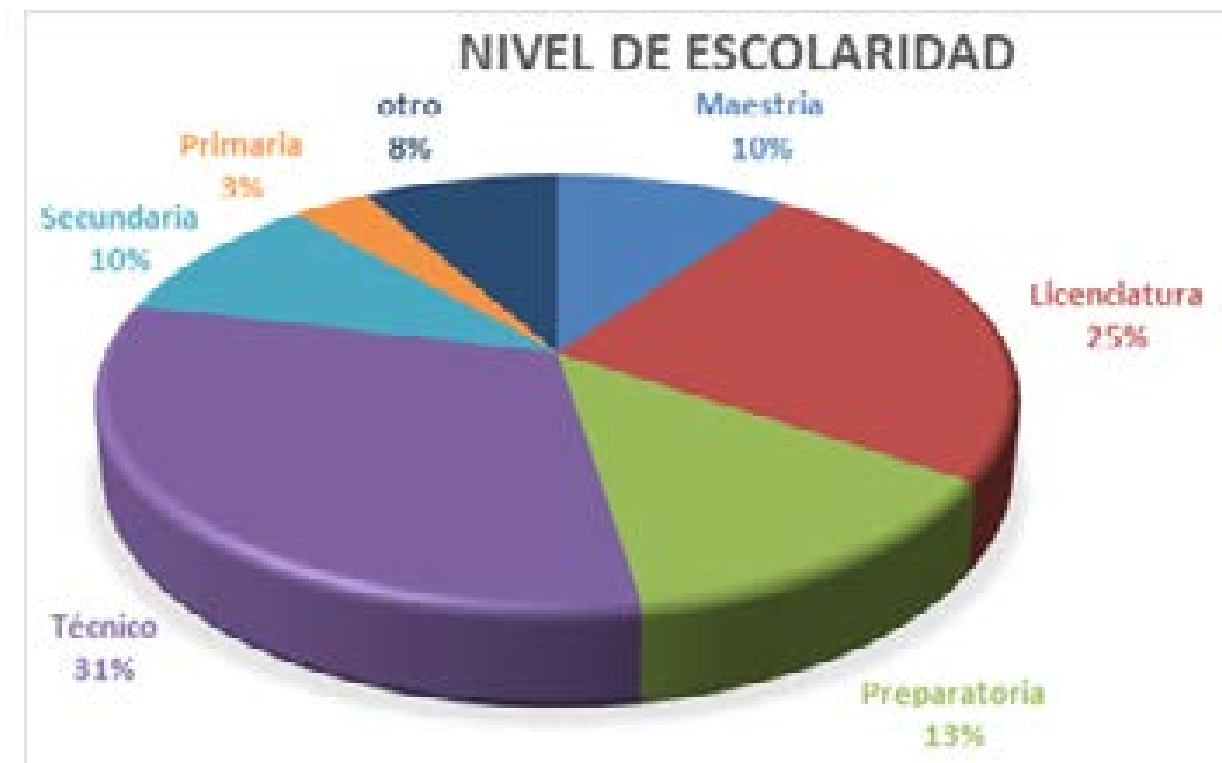

Ilustración 2. (Elaboración propia) 
De los datos anteriores se observa que el nivel de escolaridad de los alumnos entrevistados es muy heterogéneo, lo cual a su vez indica el enorme reto para la institución de ofrecer una educación para estudiantes de diferentes niveles. Esto es importante cuando se sustituye la educación presencial por la educación a distancia mediada por la informática.
En estos resultados es sorprendente el dato de cuantos estudiantes viven solos (33\%). Asimismo, también es notable en número de estudiantes que únicamente vive con el esposo(a) 23\%. Otras situaciones indican relaciones familiares más amplias: $44 \%$ vive con esposa e hijos, hijos, mamá y o hermanos.

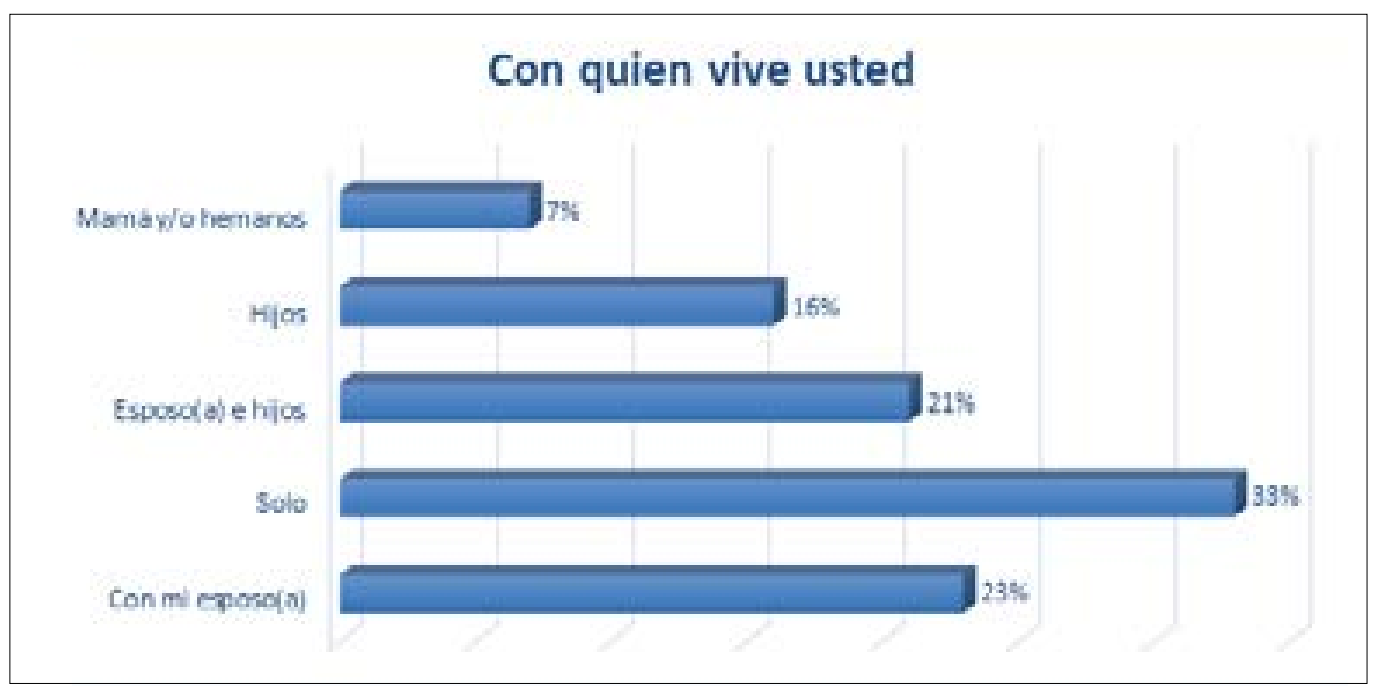

Ilustración 3 (elaboración propia)

Con quien vive el adulto mayor es de suma importancia por las necesidades de ayuda para cursar de manera virtual sus clases. El 33\% vive solo, el $23 \%$ vive con su esposo (a), el $21 \%$ vive con su esposo(a) e hijos, el $16 \%$ vive solo con los hijos y el $6 \%$ restante vive con su mamá y/o con hermanos. En este caso, la información obtenida muestra que los estudiantes que viven solos y con la esposa conjuntamente fueron más de la mitad.

Como se ha sentido en su casa durante la Pandemia

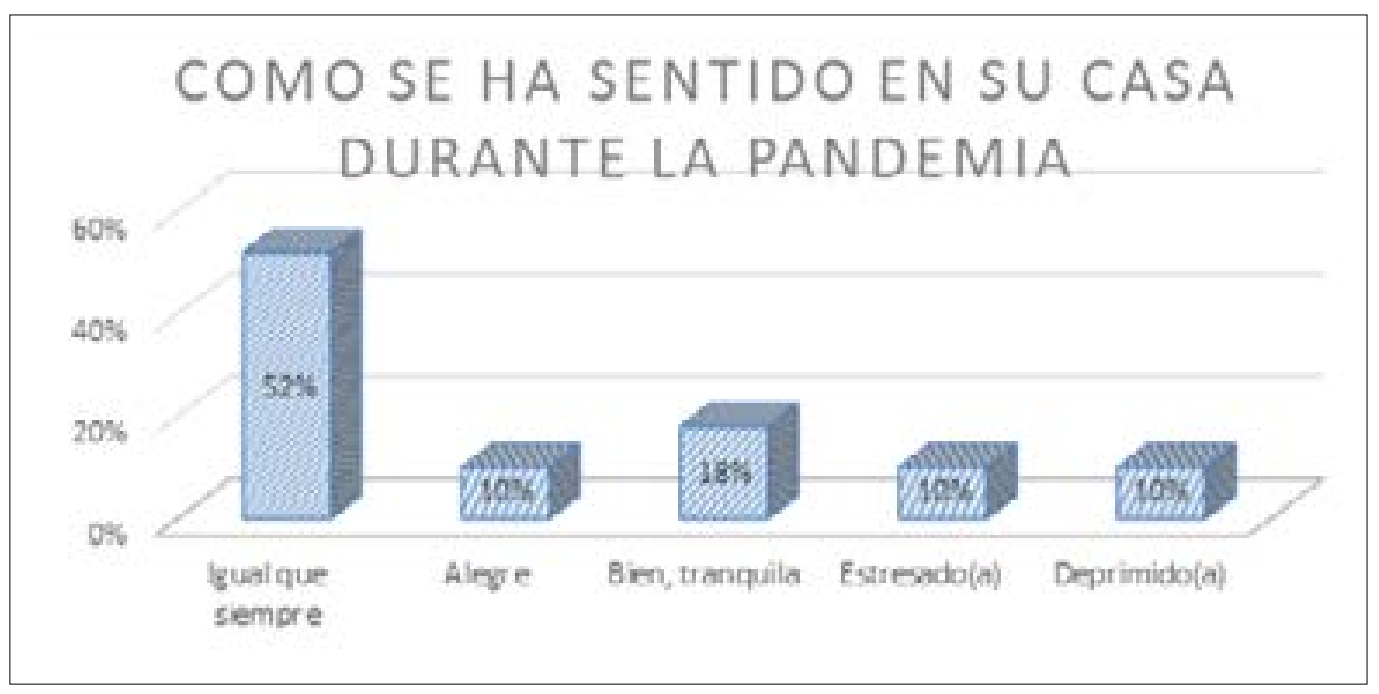

Ilustración 4 (elaboración propia) 
En cuanto al estado de ánimo de los alumnos durante la pandemia, el $52 \%$ se sintió igual, el $10 \%$ se sintió alegre, $18 \%$ manifestaron sentirse bien, tranquilo (a), 10\% deprimido (a) y $10 \%$ estresado (a). Sumando estos porcentajes, el $80 \%$ de los alumnos se ha sentido con buen estado de ánimo en su casa, el resto tuvo otros estados de ánimo menos positivos.

El estado de ánimo es un factor sumamente importante cuando se trata de la educación presencial, pero es todavía más importante cuando refiere a la educación a distancia de adultos mayores. Varios factores deben considerarse durante la estancia en casa durante la pandemia: el estado de salud (existencia de enfermedades crónico-degenerativas, la compañía de familiares, el estrés y/o depresión, entre otros. En el caso que nos ocupa la gran mayoría manifestó sentirse bien y solo el $20 \%$ de los encuestados manifestó estrés y depresión.
A pesar de este dato, bajo en comparación con el porcentaje de aquellos que no manifestaron problemas, es importante considerar que periodos prolongados de confinamiento pueden tener una incidencia negativa y podrían eventualmente provocar un aumento de este número.

\section{EL TIEMPO QUE LOS ALUMNOS CONSID- ERAN CORRECTO PARA TENER LAS SESIONES DIGITALES}

Esta pregunta fue formulada con la intención de obtener información que permita reorientar el programa. En las respuestas el $83 \%$ manifestó 2 horas, $12 \%$ una hora y $5 \%$ tres horas. Aquí indudablemente deben considerarse la edad de los estudiantes $41 \%$ del total, con edades entre 60 y 64 años; después, el grupo entre 65 y 69 años de edad constituyó el $21 \%$ de los casos; en seguida, el grupo entre 55 y 59 años agrupó al $15 \%$ de los casos. Sumados totalizaron $77 \%$.

\section{CUANTO TIEMPO CONSIDERA CORRECTO PARA TENER LAS SESIONES DIGITALES}

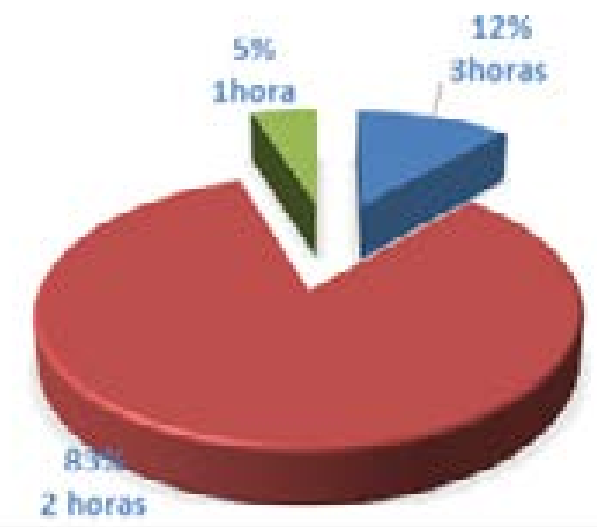

Ilustración 5 (elaboración propia) 


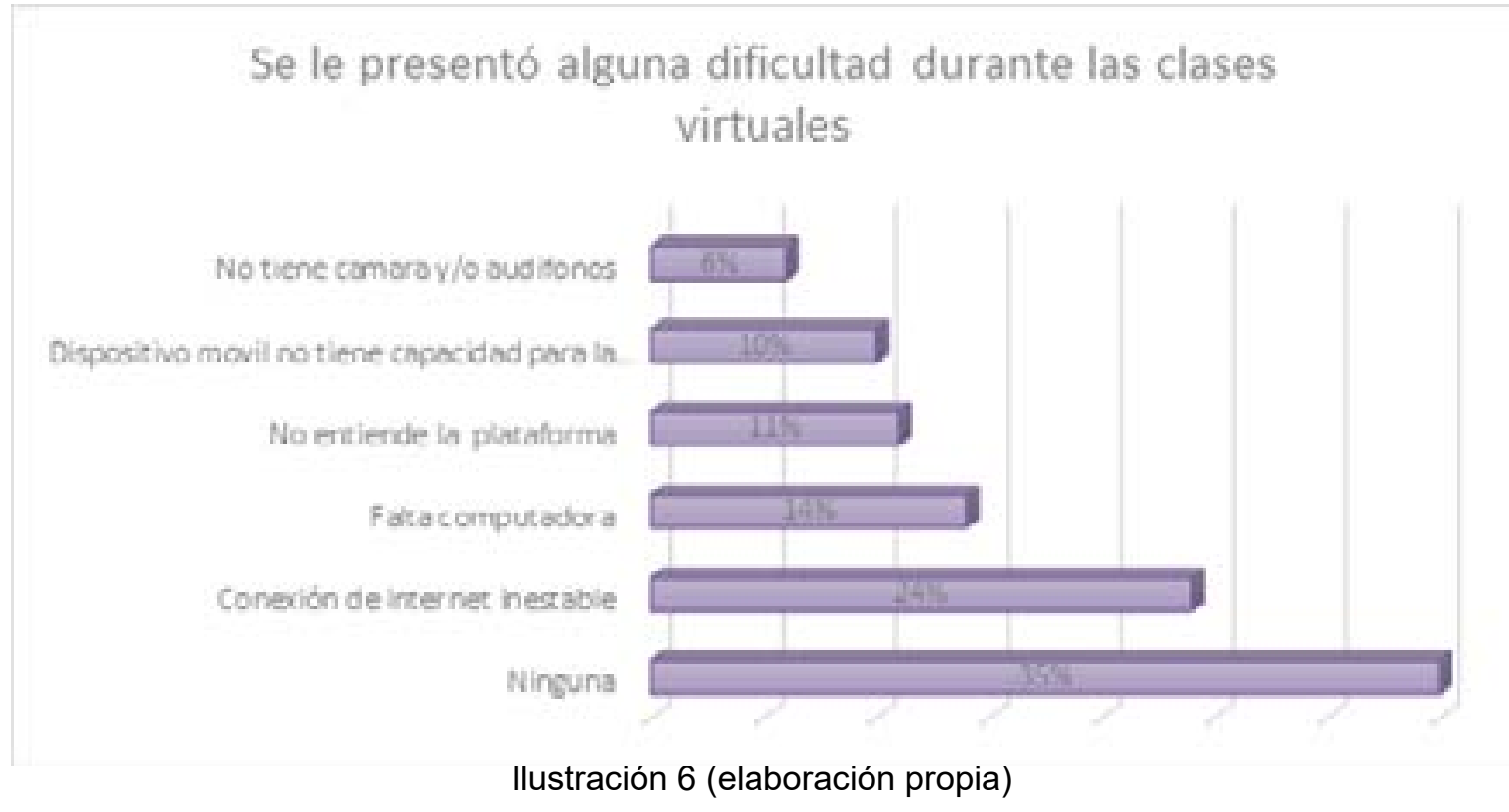

Las dificultades que manifestaron los alumnos el $54 \%$ fueron de carácter técnico, distribuidos así: para el $24 \%$ la conexión de internet era inestable, al $14 \%$ le falta computadora, $10 \%$ su dispositivo móvil no tiene capacidad para la plataforma y $6 \%$ no tiene cámara web y/o audífonos. El $35 \%$ no tuvo problemas, pero el $11 \%$ no entiende la plataforma cabe aclarar que esta cifra casi coincide con el $12 \%$ que contesto que las clases no se llevaron de manera satisfactoria. Asimismo, cuando se formuló la pregunta de si necesitó ayuda para ingresar a las clases virtuales, el $51 \%$ de los alumnos manifestó no necesitarlas.

\section{Quien le ayudaba con las tareas}

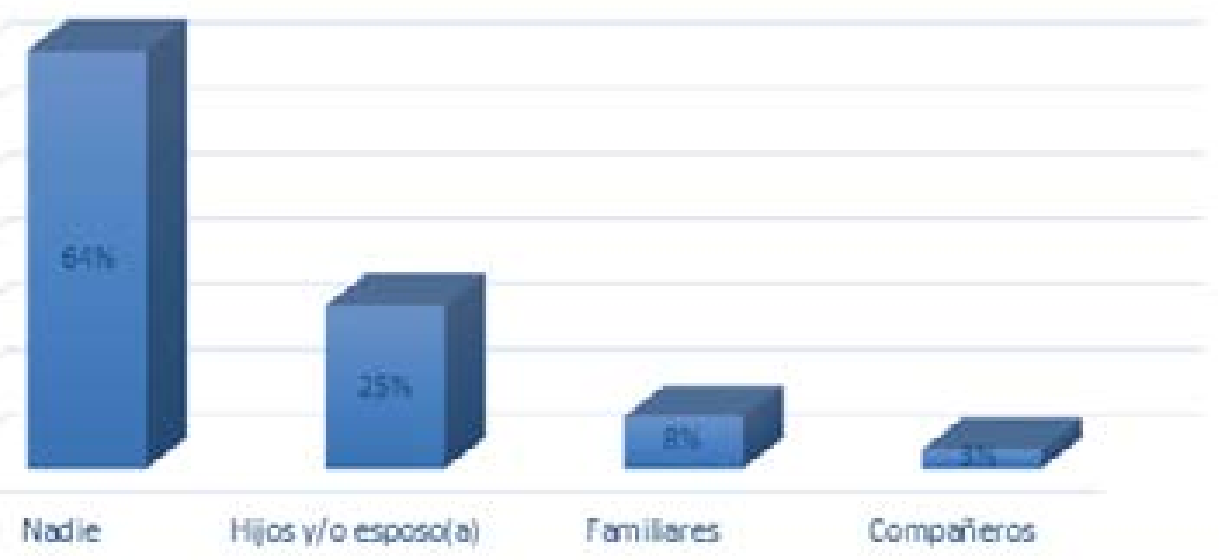

Ilustración 7 (elaboración propia) 
La mayoría de los alumnos un $64 \%$ manifestó no necesitar ayuda para realizar y enviar las tareas, los que necesitaron ayuda son apoyados por la familia, $25 \%$ por hijos y/o esposo y $8 \%$ por otros familiares y solo 3 fueron apoyados por compañeros.

\section{ALTA ESCOLARIDAD}

En la pregunta "Cómo podríamos ayudarle a tener un mejor desempeño en sus clases virtuales" los alumnos han manifestado que se han sentido apoyados y quieren seguir siéndolo pues el $41 \%$ opina que está muy bien como se ha llevado el curso, otro $23 \%$ solicita se le impartan cursos de capacitación sobre el uso de las plataformas y el $13 \%$ solicitan les envíen con anticipación material del tema, tareas, presentaciones, también solicitan más orden en la participación de los alumnos durante las sesiones digitales.

Ejemplos de respuestas textuales de los alumnos: "Estas clases fueron posible gracias a la colaboración y disposición del personal", "Su asesoría ha sido muy útil", "Contamos con todo su apoyo"," Las clases están bien". Otras respuestas fueron "Explicar cómo funcionan las plataformas", "Orden al participar, tiempo al interactuar, no interrumpir al compañero", "Cerrar los micrófonos"

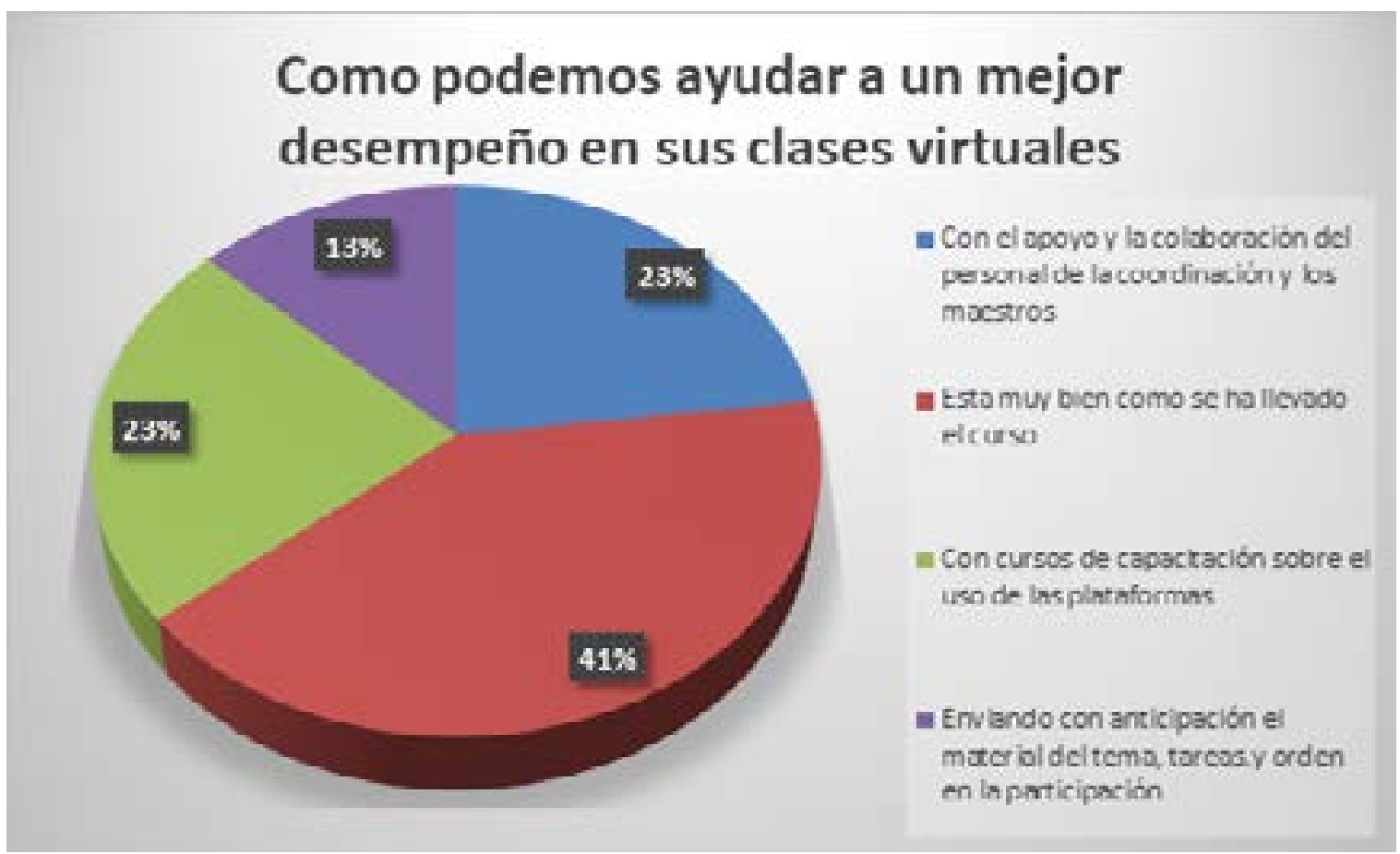

Ilustración 8 (elaboración propia) 
DE SER NECESARIO ESTARIA DISPUESTO A USAR OTRA PLATAFORMA

\begin{tabular}{|c|c|}
\hline Si está dispuesto a usar otra plataforma $(88.5 \%)$ & $\begin{array}{l}\text { No está dispuesto a usar otra plataforma } \\
\qquad(11.5 \%)\end{array}$ \\
\hline $\begin{array}{l}\text { Para estar al corriente con las clases y no } \\
\text { interrumpir el semestre. } \\
\text { Aprender y actualizarse. } \\
\text { Mientras sea necesario. } \\
\text { Sean disposiciones oficiales. } \\
\text { Mantenernos activos. } \\
\text { Que nos capaciten. } \\
\text { Si otra más simple. } \\
\text { Es un compromiso, tenemos que adaptarnos a la } \\
\text { situación. }\end{array}$ & $\begin{array}{l}\text { Con el actual tuvimos buenos resultados } \\
\text { Ya me familiaricé con la actual y empiezo a } \\
\text { entenderla }\end{array}$ \\
\hline
\end{tabular}

(Elaboración propia)

CUÁL HA SIDO SU EXPERIENCIA DIGITAL DURANTE EL COVID-19

\begin{tabular}{|l|l|}
\hline \multicolumn{1}{|c|}{$\begin{array}{c}\text { 88\% de los alumnos con } \\
\text { experiencia agradable }\end{array}$} & \multicolumn{1}{|c|}{$12 \%$ de los alumnos con experiencia no agradable } \\
\hline Novedosa, gratificante & Batallo es difícil. \\
De aprendizaje y enriquecedora. & Cansada y estresada por desconocer. \\
Agradable y entretenida. & Triste por no poder salir, no ver a la familia. \\
Todo un reto. & Deprimida \\
Aprendí el uso de las plataformas. & \\
Sin problemas. & \\
Satisfecha por la experiencia. & \\
Experiencia nueva. & \\
\hline
\end{tabular}

(Elaboración propia) 
Ante la pregunta de si considera que la clase virtual se llevó a cabo de manera satisfactoria el $88 \%$ respondió que sí.

Opinión de los profesores sobre los resultados obtenidos en el semestre enerojunio del 2020.

La encuesta se aplicó a profesores de segundo semestre que imparten las materias de: Nutrición en la edad adulta; Tardes en los museos de Nuevo León; Historia y Geografía de Nuevo León. Así también participaron 4 profesores de cuarto semestre con las materias de: Literatura;
Envejecimiento exitoso: el nuevo arte de vivir la tercera edad; Aprender a ver los estilos arquitectónicos, y Desarrollo Humano.

El $100 \%$ de los profesores manifestaron que los alumnos están interesados en la materia que les han impartido. En relación al Nivel de conocimiento del grupo sobre cada materia fue considerado suficiente para el $75 \%$ de los profesores y elevado para el $25 \%$ restante.

Ala pregunta: durante la clase invita a los alumnos al debate sobre las cuestiones explicadas. El $87.5 \%$ respondió que frecuentemente y el $12.5 \%$ dijo que pocas veces

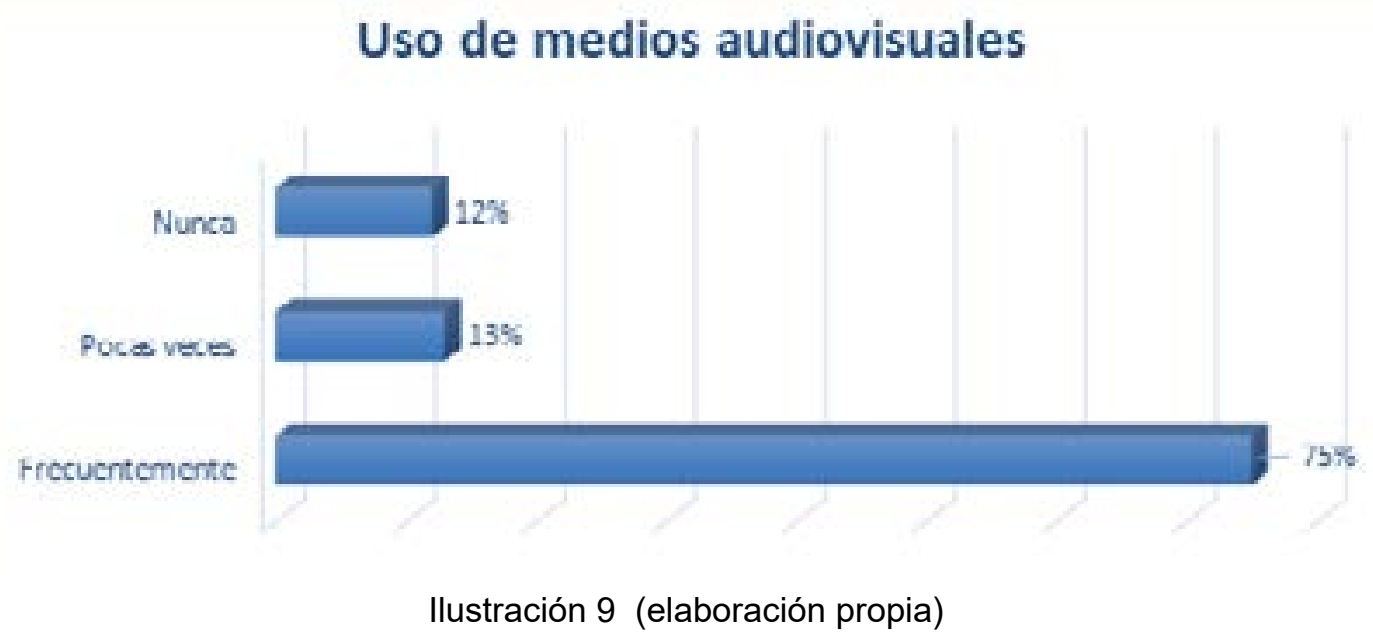

A la pregunta si para impartir su materia hace uso de medios audiovisuales tales como diapositivas, videos, audios, etc. Los profesores contestaron de la siguiente manera: $75 \%$ lo usa frecuentemente, $13 \%$ pocas veces y $12 \%$ nunca. Todos los profesores (100\%) opinan que el alumno sigue con facilidad las explicaciones, por lo tanto todos ellos consideran que no necesitan una formación previa más alta para continuar con las clases y que los alumnos se han integrado adecuadamente a la universidad.

Considera que las clases virtuales se dieron de manera satisfactoria: el $88 \%$ de los profesores manifestó que si. Los profesores expresaron que la razón para dar esta respuesta sobre las clases virtuales en donde se buscaron estrategias accesibles para impartir la materia, además de la motivación y el empeño de los alumnos para realizar las actividades programadas, revisar el material en Power Point, buscar información sobre la materia y así cumplir con las tareas. También utilizaron correo electrónico, teléfono video llamada grupos cerrados de face book y whats app.

En relación a la opinión sobre las clases virtuales por Zoom, la mayoría de los profesores manifestaron que fue buena, muy buena, excelente, amigable, interactiva y agradable. El $100 \%$ de los profesores están dispuestos a utilizar otra plataforma para continuar las clases virtuales mientras dura la contingencia. Expresaron que como docentes están dispuestos 
a usar cualquier herramienta y actualizarse, seguir activos y avanzar, para estar en constante comunicación con los alumnos.

\section{Como describe su experiencia por medio de la herramienta digital}

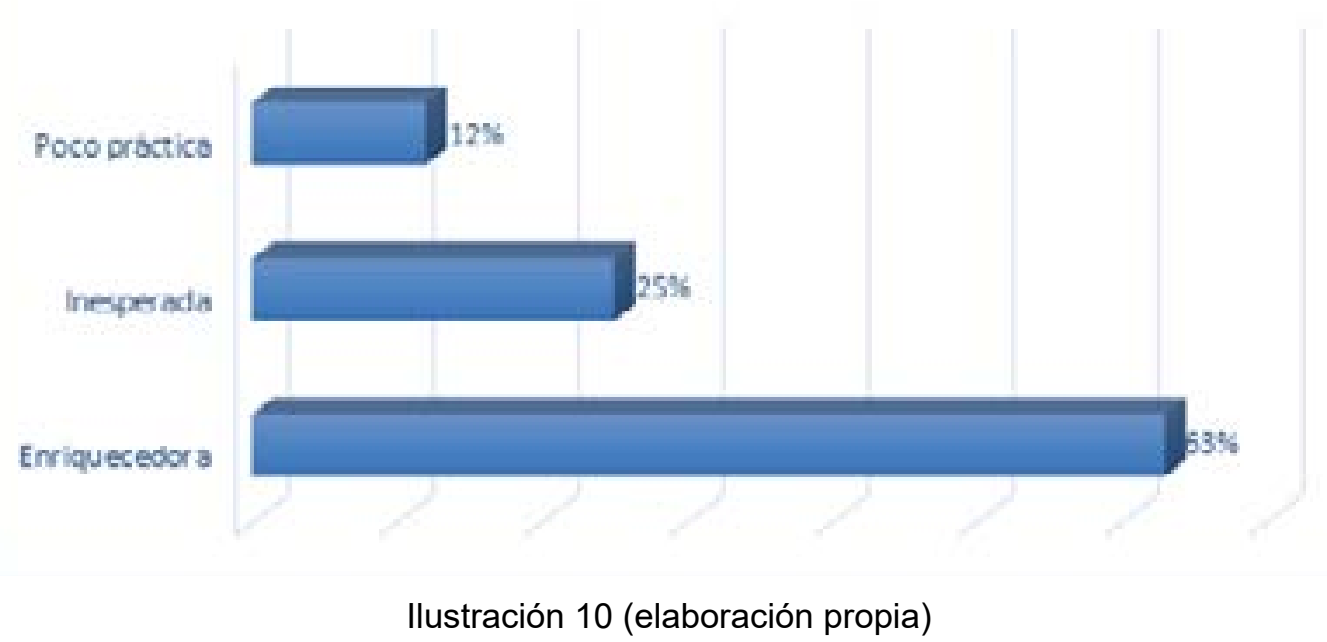

La experiencia por el uso de la herramienta digital fue expresada por los profesores de la siguiente manera: Para el $62.5 \%$ es enriquecedora, para el $25 \%$ inesperada y para el $12.5 \%$ poco práctica.

En cuanto a los objetivos establecidos en los programas de cada materia, el $75 \%$ de los profesores manifestó que si se cumplieron y para el restante $25 \%$ se cumplieron algunos.

\section{DISCUSIÓN}

En las páginas que siguen se abordará inicialmente la experiencia digital en la educación para adultos mayores frente al Covid-19 en el caso de la Universidad para los mayores de la UANL. Posteriormente se examinarán aquellos elementos que podrían favorecer la continuidad de este programa por medios virtuales y a distancia.

En relación a la experiencia digital, la información obtenida de los 61 estudiantes entrevistados reportó que la edad del mayor grupo osciló entre los 60 y 64 años ( $41 \%$ del total), esto casi coincidió con el nivel de escolaridad que fue de $44 \%$ educación media superior. Aunado a esta situación, también fue notable observar que otra parte del grupo tiene Licenciatura y Maestría 35 \% (17 y 19 años al menos de escolaridad). De aquí se desprende que se trata de un grupo con una escolaridad alta, situación que refuerza lo dicho, si la comparamos con la media nacional que es de 7 años.

Cuando se interrogó acerca de con quien viven, sorprende el dato de cuantos estudiantes viven solos (33\%). Asimismo, también es notable el número de estudiantes que únicamente vive con el esposo(a) $23 \%$. Conjuntamente fueron más de la mitad. Otras situaciones indican relaciones familiares más amplias: $44 \%$ vive con esposa e hijos, hijos, mamá y o hermanos. Estos datos son de suma importancia por las necesidades de ayuda para cursar sus clases de manera virtual.

En cuanto al estado de ánimo de los alumnos durante la pandemia, la gran mayoría mantuvo un buen estado de ánimo en su casa. Esta situación es un factor sumamente importante 
cuando se trata de la educación presencial, pero es todavía más importante cuando refiere a la educación a distancia de adultos mayores. Varios factores deben considerarse durante la estancia en casa durante la pandemia: el estado de salud (existencia de enfermedades crónicodegenerativas, la compañía de familiares, el estrés y/o depresión, entre otros. En el caso que nos ocupa solo una quinta parte de los encuestados manifestó estrés y depresión. A pesar de este dato, bajo en comparación con el porcentaje de aquellos que no manifestaron problemas, es importante considerar que periodos prolongados de confinamiento pueden tener una incidencia negativa y podrían eventualmente provocar un aumento de este número.

Tomando en cuenta la experiencia durante la pandemia, es importante el dato del tiempo que los alumnos consideran correcto para tener las sesiones digitales. Esta pregunta fue formulada con la intención de obtener información que permita reorientar el programa en la eventualidad de que se continúe con esta modalidad. Al respecto la mayoría indicó 2 horas, respuesta en la cual debe considerarse la edad de los estudiantes que se ubica en gran parte en el intervalo de 60 y 64 años, pero también sus ocupaciones personales en el hogar. Asimismo, un elemento considerable es la naturaleza del Programa que originalmente solo previó cursos en el modo presencial.

Un dato clave para la comprensión de la experiencia digital durante la pandemia Covid-19, fueron las dificultades que manifestaron los alumnos para seguir sus cursos en línea. Al respecto, poco más de la mitad exteriorizó que los problemas se relacionaron con aspectos de carácter técnico: la conexión de internet inestable; la falta de computadora; su dispositivo móvil sin capacidad para la plataforma y la no disponibilidad de cámara web y/o audífonos. De manera paralela, la tercera parte del grupo manifestó que no tuvo problemas, sin embargo, algunos de ellos tuvieron dificultad para entender la plataforma. Coincidentemente, este grupo declaró que las clases no se llevaron de manera satisfactoria.

Frente a esta problemática, es necesario aclarar lo asombroso del hecho de que un poco más de la mitad expresó que no tuvo necesidad de ayuda para ingresar a las clases virtuales y enviar las tareas. No obstante, aquellos que asumieron necesitar ayuda, fueron auxiliados en una tercera parte por la familia y otros por diversos familiares y compañeros del diplomado. Una situación que podría explicar que el primer grupo no requirió ayuda fue la alta escolaridad de los estudiantes.

Por consiguiente, en relación a aquellos que requirieron ayuda, se señaló que a pesar de haber sido apoyados por la administración del diplomado y que además quieren que se continúe el soporte, ya que consideran que está muy bien como se ha llevado el curso, requieren cursos de capacitación sobre el uso de las plataformas, además del envío con anticipación de material sobre el tema, tareas y presentaciones. Adicionalmente, apuntaron la necesidad de un orden en la participación de los alumnos durante las sesiones digitales. Esto último es interesante porque es una situación que no se había presentado en sesiones presenciales. Ejemplos de respuestas textuales de los alumnos:

"Estas clases fueron posible gracias a la colaboración y disposición del personal", "Su asesoría ha sido muy útil", "Contamos con todo su apoyo"," Las clases están bien". Otras respuestas fueron "Explicar cómo funcionan las plataformas", "Orden al participar, tiempo al interactuar, no interrumpir al compañero", "Cerrar los micrófonos" 
A pesar de que la tercera parte del grupo manifestó que no tuvo problemas para el seguimiento de los cursos, la mayoría indicó que de ser necesario estaría dispuesto a usar otra plataforma diferente a Zoom. Se destacan dos situaciones en las respuestas: "aprender y actualizarse y aceptar el compromiso de adaptarnos a la situación". En el caso de estudiantes que no están dispuestos a usar otra plataforma se externó que "hubo buenos resultados....Ya me familiaricé con la actual y empiezo a entenderla". ¿Qué se desprende de estas declaraciones? En términos generales se asume no ser refractario a la tecnología y la disposición de continuar un aprendizaje necesario en el mundo actual.

Ante la pregunta axial de "Cuál ha sido su

\section{FACTORES DE RIESGO}

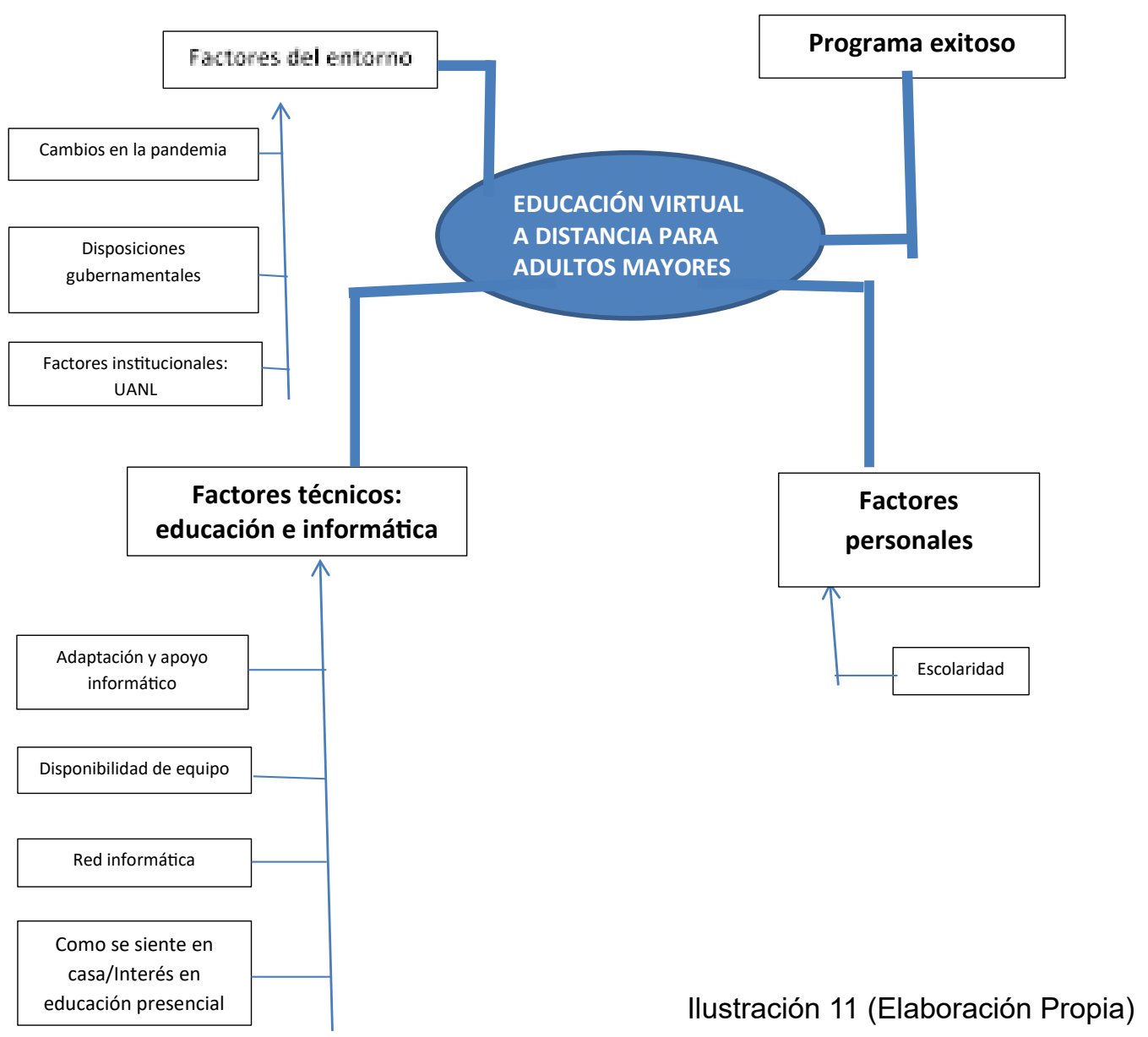

experiencia digital durante el covid-19", la respuesta de: novedosa y gratificante podría ser la respuesta generalizada en la mayoría de los estudiantes; aunque es importante no desdeñar que poco más de la décima parte de los encuestados expresó: "batallo, es difícil; cansada y estresada por desconocer; triste por no poder salir, no ver a la familia; deprimida. Estos resultados son interesantes y de cierta manera comprensible frente a la pandemia. En otra sección de este trabajo se ampliarán los comentarios.

A manera de síntesis en relación a la experiencia digital frente a la pandemia la mayoría de los estudiantes aceptó que la clase virtual se llevó a cabo de manera satisfactoria.

\section{FACTORES DE PROTECCIÓN}

(Elaboración Propia) 


\section{FACTORES DE PROTECCIÓN}

En relación a la segunda pregunta de investigación planteada para este trabajo: el examen de aquellos elementos que podrían favorecer la continuidad de este programa por medios virtuales y a distancia, es necesario mencionar que el abordaje de una prospectiva requiere la consideración de dos elementos fundamentales: el primero refiere a factores de protección en tanto que el segundo incluye factores de riesgo para la continuidad y un desempeño exitoso.

En relación a los factores de protección, son dos los podrían influir positivamente para la continuidad de la Universidad para los mayores: Por una parte, es imprescindible mencionar que en este caso se trata de un Programa exitoso y ya consolidado. Los resultados y las opiniones de los egresados así lo manifiestan. Al respecto, véase los documentos digitales de las graduaciones de ocho generaciones. Por otra parte, sin que sean menos significativos, los rasgos personales de los estudiantes que acceden al programa, son factores que contribuyen a la persistencia de la educación digital. En esta situación, destaca la escolaridad, que como fue apuntado es alta y permite el seguimiento de la comunicación digital.

Paralelamente a los factores de protección están los de riesgo. En este caso, se puede afirmar que el riesgo se hace referencia a diferentes acepciones, entre las cuales destaca la posibilidad de ocurrencia de un resultado negativo. Así, puede considerarse que el riesgo está inserto en la complejidad e incertidumbre de la sociedad actual. De aquí que su referencia conduce a aceptar una circunstancia detectable asociada con la probabilidad de estar expuesta a desarrollar un proceso. Breve, refiere a la probabilidad de ocurrencia de un evento dado... pero y he aquí lo interesante "un "determinante que puede ser modificado por medio de la intervención (Belkis, 2011).
Cuáles son los factores de riesgo para la continuidad de este programa por medios virtuales y a distancia? Hay dos factores importantes que podrían incidir en su persistencia: por una parte, los Factores del entorno; y por otra los Factores técnicos relacionados con la educación a través de la informática. En relación a los primeros, no está por demás aceptar que se trata de una circunstancia impredecible, derivada de la complejidad e incertidumbre de la sociedad actual sometida a los cambios que pueden ocurrir durante la pandemia Covid-19. No hay nada seguro, no se pueden hacer predicciones respecto al futuro de la pandemia. Es en relación a la posibilidad de ocurrencia de su amortiguamiento que se podrían prever los cambios en la educación. Solo en la medida en que si la pandemia continua existe el riesgo de una menor inscripción de estudiantes en el programa, dado que es no nuevo que estos se inscriben buscando la extensión de sus redes sociales. Se volverá sobre el tema en la última parte de este trabajo.

Asimismo dentro de los factores del entorno, es importante mencionar que las Disposiciones gubernamentales en relación a la educación influirán en las decisiones tanto personales de los que se inscriben en ese programa, como en las orientaciones institucionales de la UANL y más específicamente de la Universidad para los mayores. Actualmente las orientaciones del gobierno federal mexicano y las del gobierno estatal de Nuevo León han sido erráticas y cambiantes. No hay una definición y planeación que asegure como se desarrollarán los eventos. Lo único claro es que hasta el inicio de este mes de agosto 2020, la educación presencial se pondrá en marcha hasta que esté vigente el semáforo verde y cuando lo dispongan las autoridades estatales.

Factores de riesgo más cercanos a lo específico de este programa se relacionan con los Factores técnicos relacionados con educación a través de la informática: adaptación y apoyo (institucional, 
familiar y amigos); la disponibilidad de equipo informático y el recurso de disponibilidad personal de la Red para el acceso a la plataforma digital.

En relación a la adaptación y apoyo informático, se observó en los resultados de investigación, a pesar de que muchos estudiantes no requirieron ayuda para seguir sus cursos, muchos de ellos dependen del auxilio de otros para llevar a cabo la educación a distancia. Así, solo en la medida en que los estudiantes cuenten con este soporte podrán seguir con el programa. Asimismo, fue notable en la encuesta que en algunos casos no se disponía del suficiente equipo informático y de disponibilidad personal para el acceso a la Red, situación necesaria para comunicarse a través de la plataforma digital. Estas circunstancias se convierten en obstáculos para que estudiantes decidan no inscribirse en el Programa.

Un factor de suma importancia y quizás el de mayor peso dentro de los factores de riesgo es cómo los estudiantes se sienten en casa y su interés en la educación presencial. En relación al primero, a pesar de que la mayoría mantuvo un buen estado de ánimo en su casa, no deja de ser importante el hecho de que la quinta parte de los encuestados manifestó estrés y depresión, situación que anuncia en un caso prolongado de pandemia la agudización de estos padecimientos. En estas circunstancias el confinamiento elimina las relaciones sociales que buscan los adultos mayores cuando participan en un Programa como es el de la Universidad para los Mayores.

En este contexto es significativo citar el trabajo de Carmona, 2011, relacionado con el adulto mayor y que en este caso se relaciona íntimamente con la necesidad de acudir a la educación presencial. Para esta autora, el concepto de bienestar integral en el adulto mayor es el resultado de una combinación de factores fisiológicos que comprende la salud física del individuo; factores sociales que representan la participación del individuo dentro de la sociedad; factores mentales que refieren a la salud mental de individuo; factores económicos, relativos a su situación económica; y de factores personales, aquellas que constituye la percepción que el adulto mayor tiene de su felicidad. Con respecto a este último, diversos estudios han relacionado el bienestar personal con la actividad social del sujeto y su entorno (Herzog, Franks, Markus y Holmberg, 1998; Okun, Stock, Haring y Witter, 1984, citados en Carmona, 2011) donde la actividad social juega un papel determinante incrementando su autoestima y generando un sentimiento de bienestar hacia los cambios propios de la edad. De esta manera, las actividades sociales realizadas por el individuo dan significado a su existencia permitiéndole una integración plena en la sociedad, brindándole un sentido de pertenencia social generada por "la autoconciencia de ser socialmente aceptado y de la experiencia de sentirse incluidos en la corriente misma de la vida" (OMS, 1989, citado en Carmona, 2011).

Así de acuerdo a Carmona (2011) es fácil identificar a un adulto mayor que ha experimentado el bienestar personal por las características que posee como la sociabilidad, la seguridad en sí mismo, suelen ser personas positivas con su entorno y poseen cualidades que los ayudar a cumplir las metas que se han establecido en la vida y se perciben saludables, a diferencia de los adultos mayores que no ha experimentado dicho bienestar personal que suelen referir problemas de salud e infelicidad.

Por lo tanto, en el envejecimiento, la socialización de las personas mayores aporta considerables beneficios a su bienestar integral, al permitir la continuidad de la integración del individuo en la sociedad, al contrario del aislamiento y la soledad que influyen directamente en el riesgo de sufrir demencia a medida que se acentúan (Bessuk, Glass y Berkman, 1999 citado en Carmona 2011). La soledad ocasiona el mayor deterioro en los aspectos que comprenden el bienestar personal de los adultos mayores. Es esta 
situación, precisamente, la que está en el centro de los factores de riesgo para la continuidad de programas a distancia, sobre todo en el caso de la Universidad de los mayores de la UANL.

\section{REFLEXIONES FINALES}

Es posible aseverar que la estrategia digital aplicada por el Programa Universidad para los Mayores tuvo un resultado positivo para los estudiantes adultos mayores que experimentaron la continuación del semestre en línea. La adaptabilidad al mundo digital está relacionada con el nivel de escolaridad de los estudiantes, manifestando que los problemas más frecuentes con los que se encontraron fueron de carácter técnicos como la conexión de internet inestable; la falta de computadora; su dispositivo móvil sin capacidad para la plataforma y la no disponibilidad de cámara web y/o audífonos.

En lo que refiere al estado de ánimo de los estudiantes durante la pandemia, a pesar de que la mayoría de los estudiantes manifestaron mantener un buen estado de ánimo, no deja de ser importante el hecho de que la quinta parte de los encuestados manifestó estrés y depresión, situación que anuncia en un caso prolongado de pandemia la agudización de estos padecimientos, poniendo en riesgo el bienestar personal y la continuidad de los programas a distancia en el caso de la Universidad para los Mayores.

En este contexto, y a manera de propuesta, será necesario el desarrollo de redes de acompañamiento a distancia que garanticen el fortalecimiento del bienestar personal del estudiante adulto mayor durante este periodo de pandemia.

\section{REFERENCIAS BIBLIOGRAFICAS}

ANUIES (2013), Educación continua. México: Asociación Nacional de Universidades e Instituciones de Educación Superior. En línea en: http://www.anuies.mx/content.

\section{php?varSectionID=144}

ANUIES y Secretaría de la Presidencia (s/f), Manual para la integración de personas con discapacidad en las instituciones de educación superior. México. En línea en: http://www. conadis.salud.gob.mx/descargas/pdf/2-manualuniversidad-incluyente.pdf

Atarama, T. (5 de abril de 2020). La educación virtual en tiempos de pandemia. Recuperado el 29 de mayo de 2020, de Universidad de Piura: http://udep.edu.pe/hoy/2020/la-educacionvirtual-en-tiempos-de-pandemia/

Belkis, G. (2000), "Equidad, desarrollo y ciudadanía: una visión global", en: Equidad, desarrollo y ciudadanía, 3 al 7 de abril. LC/G. 2071(SES. 28/3). Capítulo 2. CEPAL. México

Carmona, S. (2011). "Envejecimiento Activo: La clave para vivir más y mejor". Editorial: Universidad Autónoma de Nuevo León. U.A.N.L. ISBN:978-607-433-574-3.

Castillo, D., \& Vela, F. (2005). "Envejecimiento demográfico en México. Evaluación de los datos censales por edad y sexo, 1970-2000". Papeles de población, 11(45). Obtenido de https:// rppoblacion.uaemex.mx/article/view/8705

Cortés, F. Consideraciones sobre la marginación, la marginalidad, marginalidad económica y Exclusión Social. Papeles de población, No. 047, pp. 71-84. México.

Engler, A., \& Peláez, M. (2002). Más vale longevidad de un estudio en el Cono Sur. Obtenido de Banco Interamericano de desarrollo/ Organización Panamericana de salud: http:// biblioms.dyndns.org/libros/Adulto\%20mayor/ M\%C3\%A1s_vale_por_viejo.pdf.

Ferrante, P. (abril de 2020). La educación virtual, más allá de la pandemia. Recuperado el 2020 de mayo de 28, de Perfil.com: https://www.perfil. com/noticias/opinion/coronavirus-educacionvirtual-mas-alla-pandemia-covid19.phtml 
Fuerte, K. (17 de abril de 2020). ¿Cómo afecta la brecha digital a los adultos mayores? Recuperado el 28 de mayo de 2020, de Observatorio de Innovación Educativa: https:// observatorio.tec.mx/edu-news/brecha-digitaladultos-mayores-exclusion-social

Gobierno de la República (2013), Plan Nacional de Desarrollo, 2013-2018. México: Diario Oficial de la Federación. En línea en: http://pnd.gob.mx/ Ham, R. (2003). El envejecimiento en México. El siguiente reto de la transición demográfica. México: Porrúa y El Colegio d ela Frontera Norte.

INEGI (2013), Censo de población y vivienda México, 2010. Aguascalientes: Instituto Nacional de Estadística, Geografía e informática. En línea en: http://www.censo2010.org.mx/

Kemelmajer, C. (9 de abril de 2020). Educación en tiempos de pandemia: consejos de especialistas para enriquecer las aulas virtuales. Recuperado el 28 de mayo de 2020, de https://www.conicet. gov.ar/educacion-en-tiempos-de-pandemiaconsejos-de-especialistas-para-enriquecer-lasaulas-virtuales/

Laparra, M., Gaviria, M. y Aguilar, M. (1998), "Aproximaciones a la exclusión social", en: Hernández J. y M. Olza (Eds.). La exclusión social: Reflexión y acción desde el Trabajo Social, pp.19-50. Pamplona: Eunate.

López, N. (15 de abril de 2020). Educación e inequidad virtual en tiempos de Pandemia. Recuperado el 28 de mayo de 2020, de La Izquierda Diario: http://www.laizquierdadiario. com/Educacion-e-inequidad-virtual-en-tiemposde-Pandemia

Medina, T. (2013), Materiales para elaborar la conferencia: calidad de vida y bienestar subjetivo de los adultos mayores. Murcia: Facultad de Trabajo Social de la Universidad de Murcia.

Minujin, A., "Vulnerabilidad y Exclusión Social en América Latina", en Bustelo, E. y Minujin, A. (Editores), Todos entran. Propuesta para sociedades incluyentes, Unicef-Santillana, Bogotá, 1998. págs. 163-165.

National Institute on Aging (2001). "World's Older Population Growing by Unprecedented 800,000 a Month", en: NIH News Release. En línea en: http://www.nia.nih.gov/news/pr/2001/1213.htm.

Paniagua, M. (2010), "Los otros frente a nosotros: la integración de las personas con discapacidad como un derecho humano", en: Martha Vergara Fregoso. Desarrollo humano y diversidad. Cuadernos temáticos de investigación educativa para el desarrollo humano, pp. 57-72. Guadalajara: Red de Posgrados de Educación/ Consejo Estatal de Ciencia y Tecnología de Jalisco.

Puerta, A., Marrero J. y Fernández, E. (2011), “¿Por qué está satisfecho el alumnado de la Universidad para Mayores? Un análisis comparativo con el alumnado de la Licenciatura de Pedagogía", en: IV Encuentro Iberoamericano de Universidades para Mayores, Vol. I. Alicante: Asociación Estatal de Universidades para los Mayores.

Red Experimento Latam. (03 de abril de 2020). Desafíos y oportunidades para la educación virtual en tiempos de cuarentena. Recuperado el 28 de mayo de 2020, de Red STEM Latinoamérica: https://experimento.lat.siemensstiftung.org/desafios-y-oportunidades-para-laeducacion-virtual-en-tiempos-de-cuarentenal

Saraví, G. (2009), Transiciones vulnerables, juventud, desigualdad y exclusión en México. México: CIESAS.

Semana. (04 de abril de 2020). Recuperado el 28 de mayo de 2020, de Columna Educación: https://www.semana.com/educacion/articulo/ cinco-casos-exitosos-de-educacion-virtual-enmedio-de-la-pandemia/663599

Silva, L. A., \& López, R. E. (2014). EDUCACIÓN DE ADULTOS MAYORES Y EN DIVERSIDAD. LA EXPERIENCIA DE LA UNIVERSIDAD 
AUTÓNOMA DE NUEVO LEÓN, MÉXICO. Revista Lugares de Educação, 30-48.

Silva, R. (10 de abril de 2020). Educación virtual en tiempos de la pandemia: ¿un nuevo paradigma? Recuperado el 2020 de mayo de 28, de Actualidad en psicología: https://www. actualidadenpsicologia.com/educacion-virtualpandemia-nuevo-paradigma/

Tuirán, R. (1999). "Retos y oportunidades demográficas de México en el Siglo XXI", en: La situación demográfica de México. México: Consejo Nacional de Población. En línea en: http://conapo.gob.mx/publicaciones/Otras/ Otras4/22.pdf.

Universidad Autónoma de Nuevo León (2012), Plan de Desarrollo Institucional UANL 20122020. En línea en: http://www.uanl.mx/sites/ default/files/documentos/universidad/pdi-202026abril.pdf

Universidad de Alicante. (2011). Actas del IV Congreso Iberoamericano de Universidad para Mayores. Recuperado el 29 de mayo de 2020, de http://www.fimte.fac.org.ar/ doc/21CIUUMM2011 tomo II.pdf

Universidad de Salamanca. (1998). Encuentros Nacionales de Programas Universitarios para Personas Mayores. Recuperado el 28 de mayo de 2020, de http://www.aepumayores.org/es/ contenido/ii-encuentro-nacional-de-programasuniversitarios-para-mayores-alcal\%C3\%A!

Universidad de Valladolid. (2011). Jornadas sobre Asociacionismo en los Programas Universitarios de Mayores. Recuperado el 29 de mayo de 2020, de http://www.publicaciones.uva. es/UVAPublicaciones-12761-Generalidadesy-alta-divulgacion-Universidad-y-CulturaJornadas-sobre-Asociacionismo-en-losProgramas-Universitarios-de-Mayores-Diezanos-de-encuentros.aspx.

Universidad de Zamora. (2004). Encuentros Nacionales de Programas Universitarios para
Personas Mayores. Recuperado el 29 de mayo de 2020, de http://www.aepumayores.org/sites/ default/files/Actas_VIII_Encuentro_PUPM_ Zamora_2004.pdf

Zaude, H. (2010). Análisis estructural prospectivo: analizar las variables claves de futuro. Recuperado el 28 de mayo de 2020, de http://www.prospectiva.eu/blog/606 